Check for updates

Cite this: RSC Adv., 2017, 7, 28909

\title{
Fabrication and properties of a superhydrophobic film on an electroless plated magnesium alloy $\dagger$
}

\begin{abstract}
Jing Yuan, ${ }^{\text {ab }}$ Jihui Wang, (DD*ac Kaili Zhang ${ }^{c}$ and Wenbin $\mathrm{Hu}^{\mathrm{c}}$
A superhydrophobic coating is an outstanding barrier layer isolating the substrate from the corrosive medium, thus enhancing corrosion resistance. In this paper, a superhydrophobic film on the electroless $\mathrm{Ni}-\mathrm{P}$ plated AZ61 magnesium alloy was fabricated via hydrothermal method and subsequently immersed in stearic acid solution to improve its anti-corrosion properties and self-cleaning performance. The surface morphology, structure, chemical composition and properties were investigated using scanning electron microscope (SEM), X-ray diffractometer (XRD), Fourier-transform infrared spectrophotometer (FTIR), micro-Raman spectrometer, optical contact angle meter and electrochemical workstation. The results showed that the plated $\mathrm{Ni}-\mathrm{P}$ surface was hydrophilic, but it turned superhydrophobic after modification by hydrothermal reaction and stearic acid. We found the temperature and time of hydrothermal reaction could influence the morphology and wettability of the superhydrophobic nature deeply, and the petal-shaped nanosheets resulting at higher temperature had a higher hydrophobicity than the lemongrass-like nanostructures at the lower temperature. The maximum contact angle of 155.6 $\pm 0.3^{\circ}$ and a sliding angle about $2^{\circ}$ were obtained under conditions of reaction temperature of $120^{\circ} \mathrm{C}$ and reaction time of $15 \mathrm{~h}$. Meanwhile, the chemical stability, mechanical durability and self-cleaning performance of the formed superhydrophobic film were examined. And the potentiodynamic polarization and electrochemical impedance spectroscopy results indicated the corrosion resistance of the AZ61 substrate was improved a lot in $3.5 \% \mathrm{NaCl}$.
\end{abstract}

Received 19th April 2017 Accepted 26th May 2017 DOI: $10.1039 / \mathrm{c} 7 \mathrm{ra04387b}$ rsc.li/rsc-advances

\section{Introduction}

Magnesium and magnesium alloys as important engineering materials are potentially applied in automobile, aerospace, electronic communication and recreational industries due to low density, high strength and excellent machinability., ${ }^{1,2}$ Nevertheless, their chemical character is very active and they are susceptible to corrosion in seawater or humid atmosphere with organic/ inorganic acids, which limits large-scale application of magnesium and its alloys. ${ }^{3,4}$ Therefore, various methods are used to improve their corrosion resistance, such as chemical conversion, micro-arc oxidation, electroplating and electroless plating. ${ }^{5-7}$

The superhydrophobic surfaces with water contact angle larger than $150^{\circ}$ and sliding angles smaller than $10^{\circ}$ have arrested much attention of scholars in recent years because of their potential application in self-cleaning, anti-icing, antifouling and anticorrosion..$^{8-13}$ The reason for anticorrosion

${ }^{a}$ State Key Laboratory of Hydraulic Engineering Simulation and Safety, Tianjin University, Tianjin 300072, P. R. China.E-mail:jhwang@tju.edu.cn

${ }^{b}$ College of Physics Electronic Information Engineering, Qinghai University for Nationalities, Xining, Qinghai 810007, P. R. China

${ }^{c}$ Tianjin Key Laboratory of Composite and Functional Materials, School of Materials Science and Engineering, Tianjin University, Tianjin 300072, P. R. China

$\dagger$ Electronic supplementary information (ESI) available. See DOI: 10.1039/c7ra04387b mechanism of superhydrophobic surfaces is that a large amount of air is trapped in the valleys between the rough structure of superhydrophobic surface thus the migration of corrosion ions is inhibited by these air cushion. Liu et al. fabricated biomimetic $\mathrm{CeO}_{2}$ hydrophobic films on AZ91D magnesium alloy by an immersion process and then modified with DTS, the maximum water contact angle reached to $146.7 \pm 2^{\circ}$ and the hydrophobic coating possessed better corrosion resistance than magnesium alloy matrix. ${ }^{14}$ Cui et al. fabricated a hydrophobic surface through the micro-arc oxidation and subsequent modified with stearic acid on AZ31 Mg alloy, achieving a maximum water contact angle of $151.5^{\circ}$ and the hydrophobic MAO coatings effectively inhibits pitting corrosion of the Mg alloy. ${ }^{15}$ Therefore, hydrophobic modification was a great way to improve the corrosion resistance of metal surfaces.

Hydrothermal method is a low cost, reproducibility and environmental friendly method to in situ synthesize nanostructure on the metal substrates, and the nanostructures growing on the metal surface could increase the surface roughness and benefit to trapping air. ${ }^{16,17} \mathrm{Ou}$ et al. fabricated a superhydrophobic surface on AZ91D magnesium alloy via hydrothermal reaction in pure water, followed by modification with $1 H, 1 H, 2 H, 2 H$-perfluorooctyltriethoxysilane (PFOTES), and the surface exhibited more stable and effective qualities in corrosion protection as compared with the superhydrophobic 
surface fabricated using chemical etching. ${ }^{18}$ Wan et al. obtained a superhydrophobic surface on ZK60 magnesium alloy via hydrothermal reaction in a mixture of pure water, ethanol and stearic acid, and the water contact angle is about $158.5^{\circ} \cdot{ }^{19} \mathrm{Zhang}$ et al. constructed a superhydrophobic surface on AZ80 magnesium alloy via hydrothermal reaction in pure water with different $\mathrm{pH}$ values, and then modified with triethoxypropylsilane (PTES). ${ }^{20}$ These results all proved that hydrothermal method could form superhydrophobic surface with high quality. However, there still exist two drawbacks for this method. One is the improvement of corrosion resistance for $\mathrm{Mg}$ alloys is limited only by a thin superhydrophobic film, and the other is generally Al-enriched $\mathrm{Mg}$ alloys fabricating superhydrophobic film via this way, because the main components of the superhydrophobic film is $\mathrm{Mg}-\mathrm{Al}$ layered double hydroxide. ${ }^{\mathbf{1 8 - 2 2}}$

Herein, we first fabricated a superhydrophobic film on the surface of electroless Ni-P coating of AZ61 magnesium substrate using hydrothermal method. The influence of hydrothermal reaction conditions, such as the temperatures and the reaction times on the superhydrophobic film morphology and properties were investigated deeply. The formed superhydrophobic film has excellent stability in various $\mathrm{pH}$, salinity conditions and abrasion test, as well as the outstanding self-cleaning performance. Both the superhydrophobic layer and the Ni-P coating can protect the AZ61 substrate and improve corrosion resistance significantly. Moreover, electroless Ni-P plating is widely used in industrial field on various substrates, so our paper could provide an efficient method to fabricate superhydrophobic surface with robust corrosion resistance on other metals.

\section{Experimental}

\subsection{Materials}

The chemical composition of the AZ61 magnesium alloy was 5.92 wt\% Al, 0.49 wt\% Zn, 0.15 wt\% Mn, 0.037 wt\% Si, 0.003 wt $\%$ $\mathrm{Cu}, 0.007 \mathrm{wt} \% \mathrm{Fe}$ and the remaining proportion was $\mathrm{Mg}$. The dimensions of all samples were $10 \mathrm{~mm} \times 10 \mathrm{~mm} \times 4 \mathrm{~mm}$. All of the reagents were analytical grade and deionized water with a resistivity of $18.5 \mathrm{M} \Omega \mathrm{cm}$ was used in all of experiments. The substrates were mechanically grounded with SiC papers of successively finer grit down to 2000 grit, ultrasonically degreased $10 \mathrm{~min}$ in acetone and dried in air. Pretreatment steps of AZ61 magnesium alloy should be shown below. The substrate was degreased in an alkaline solution containing $10 \mathrm{~g} \mathrm{~L}^{-1} \mathrm{Na}_{3} \mathrm{PO}_{4}$ $\cdot 12 \mathrm{H}_{2} \mathrm{O}$ and $50 \mathrm{~g} \mathrm{~L}{ }^{-1} \mathrm{NaOH}$ at $65{ }^{\circ} \mathrm{C}$ for $10 \mathrm{~min}$. To remove the oxide film, the pretreated magnesium alloy was immersed in acid solution containing $60 \mathrm{~mL} \mathrm{~L}^{-1} \mathrm{H}_{3} \mathrm{PO}_{4}, 30 \mathrm{~g} \mathrm{~L}^{-1} \mathrm{H}_{3} \mathrm{BO}_{3}$, and $40 \mathrm{~g} \mathrm{~L}^{-1} \mathrm{NH}_{4} \mathrm{HF}_{2}$, for $40 \mathrm{~s}$ at room temperature. At last, the pretreated magnesium alloy was activated in $\mathrm{HF}\left(385 \mathrm{~mL} \mathrm{~L}^{-1}\right)$ solution for $8 \mathrm{~min}$ at room temperature. The sample thoroughly was cleaned with deionized water between each step.

\subsection{Fabrication of superhydrophobic film}

Fig. 1 shows a schematic diagram of our fabrication method, which is made up of three steps, details were follows:
2.2.1 Electroless nickel plating. The electroless plating bath used was composed by $20 \mathrm{~g} \mathrm{~L}^{-1} \mathrm{NiSO}_{4} \cdot 6 \mathrm{H}_{2} \mathrm{O}, 20 \mathrm{~g} \mathrm{~L}^{-1}$ $\mathrm{NaH}_{2} \mathrm{PO}_{2} \cdot \mathrm{H}_{2} \mathrm{O}, 5 \mathrm{~g} \mathrm{~L}^{-1} \mathrm{H}_{3} \mathrm{C}_{6} \mathrm{H}_{5} \mathrm{O}_{7} \cdot \mathrm{H}_{2} \mathrm{O}, 10 \mathrm{~g} \mathrm{~L}^{-1} \mathrm{NH}_{4} \mathrm{HF}_{2}, 12$ $\mathrm{mL} \mathrm{L}^{-1} \mathrm{HF}, 15 \mathrm{~g} \mathrm{~L}^{-1} \mathrm{CH}_{3} \mathrm{COONH}_{4}$ and $1 \mathrm{mg} \mathrm{L}^{-1} \mathrm{CH}_{4} \mathrm{~N}_{2} \mathrm{~S}$ under $\mathrm{pH}$ value of 5.5, which was adjusted by the addition of $\mathrm{NH}_{3} \cdot \mathrm{H}_{2} \mathrm{O}$. The temperature of plating bath was $85^{\circ} \mathrm{C}$ which was fulfilled by thermostatic water bath, and the plating time was $180 \mathrm{~min}$. After plating, the sample was taken from the bath, and then cleaned with deionized water and dried with electric drier.

2.2.2 Hydrothermal method. First, $0.1422 \mathrm{~g} \mathrm{Ni}\left(\mathrm{NO}_{3}\right)_{2} \cdot 6 \mathrm{H}_{2} \mathrm{O}$ was dissolved into $50 \mathrm{~mL}$ pure ethanol under vigorous stirring. After stirring for $20 \mathrm{~min}$, the homogeneous solution was transferred into a Teflon-lined stainless steel autoclave with a volume of $100 \mathrm{~mL}$, and then a piece of cleaned magnesium alloy with Ni-P coating was immersed into it. The autoclave was tightly sealed and heated at $100-160{ }^{\circ} \mathrm{C}$ for $9-24 \mathrm{~h}$ in an oven, then cooled down to room temperature naturally. The sample with ordered nanostructure was fetched out and rinsed with deionized water several times.

2.2.3 Modification. The sample with ordered nanostructure was immersed into an ethanol stearic acid solution $\left(0.01 \mathrm{~mol} \mathrm{~L}^{-1}\right)$ at room temperature for $5 \mathrm{~h}$. Finally, the sample was rinsed with deionized water and dried using a dryer.

\subsection{Characterization}

The surface morphology was observed by Hitachi S-4800 field emission scanning electron microscopy (FESEM) operated at 5.0 $\mathrm{kV}$. The structure of coating was measured by D/MAX-2500 X-ray diffractometer (XRD). The functional groups on the film were identified by BIO-RAD3000 Fourier-transform infrared (FT-IR) spectroscopic analysis and DXR Microscope micro-Raman spectrometer (with an excitation wavelength of $532 \mathrm{~nm}$ ).

\subsection{Wettability}

The water contact angle and the sliding angle were measured with a water drop volume of $7 \mu \mathrm{L}$ using JC2000D optical contact angle meter at ambient temperature. In addition, the contact angle of superhydrophobic film in solutions with different $\mathrm{pH}$ values ranging from 1-14 and concentrations of $\mathrm{NaCl}$ changing from 1-5 $\mathrm{mol} \mathrm{L}^{-1}$ were measured after submerged into the solutions for $3 \mathrm{~h}$. The $\mathrm{pH}$ value of solution was adjusted by hydrochloric acid and sodium hydroxide. The values reported are averages of five measurements made on different positions of the sample surface.

\subsection{Corrosion resistance}

The polarization curve and electrochemical impedance spectroscopy (EIS) of AZ61 substrate, Ni-P coating and superhydrophobic film were measured in $3.5 \% \mathrm{NaCl}$ solution at room temperature by using Autolab 302 electrochemical workstation. A three-electrode system with the sample by an exposed area of $1 \mathrm{~cm}^{2}$ as working electrode, a platinum electrode as counter electrode and a saturated calomel electrode (SCE), which standard potential is $0.2415 \mathrm{~V}$ at $25{ }^{\circ} \mathrm{C}$ as reference electrode was employed in the test. 


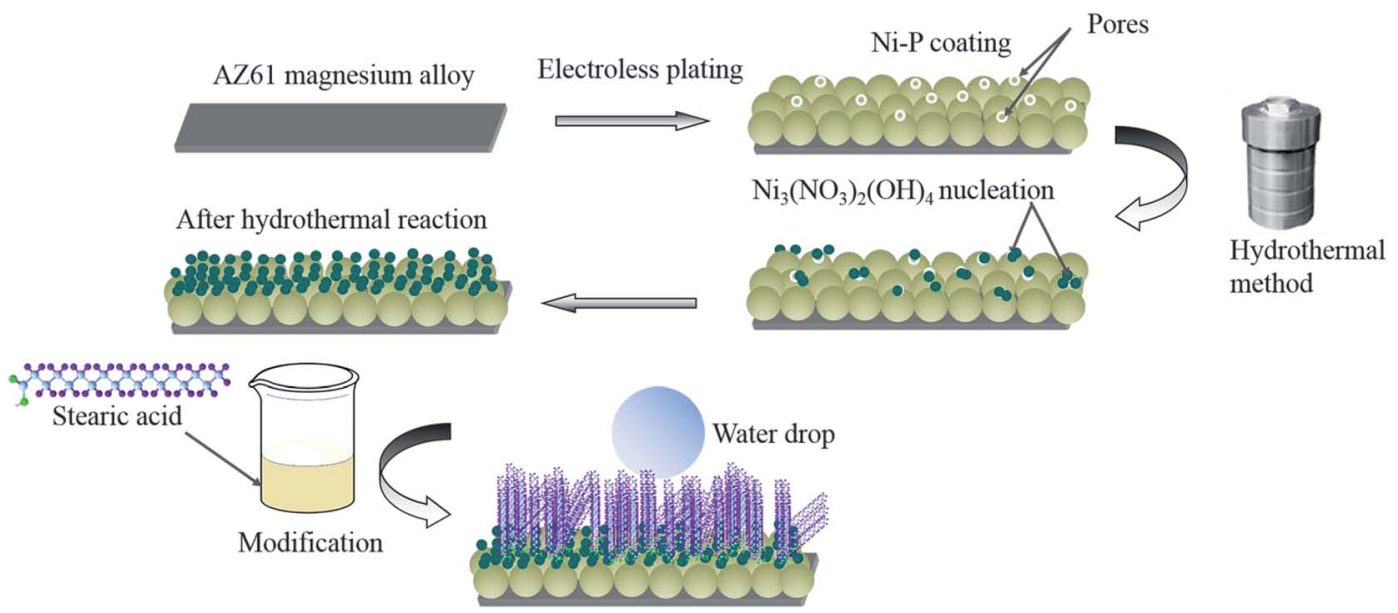

Fig. 1 Flow chart of fabrication process for superhydrophobic film on AZ61 alloy.

The potentiodynamic polarization experiments were performed at a scan rate of $0.1667 \mathrm{mV} \mathrm{s}^{-1}$. And EIS measurements were carried out at the open circuit potential with a $10 \mathrm{mV}$ amplitude AC signal and the applied frequency ranged from 100 $\mathrm{kHz}$ to $0.01 \mathrm{~Hz}$. The electrochemical parameters for the EIS date were calculated by applying ZsimpWin software under the given equivalent circuits.

\section{Results and discussion}

Fig. 2 shows the FESEM images electroless Ni-P coating after plating $180 \mathrm{~min}$. The surface roughness enhanced after plating because Ni-P coating consists of a nodular structure with nodules size about several micrometers. However, some pores occurred on the surface due to the hydrogen release. Electroless $\mathrm{Ni}-\mathrm{P}$ coating on magnesium alloy is cathodic coating, and pores are inevitable, so it provided little protection. The water contact angle of the surface after electroless plating is $67^{\circ}$ and was be hydrophilic. It is well known that a surface with a micro/ nanostructured roughness is the key step in fabricating a superhydrophobic film, ${ }^{23,24}$ nickel nodules provide microstructure, and hydrothermal reaction would produce nanometer structure on the surface.

\subsection{Hydrothermal reaction}

The reaction temperature and reaction time can influence the nanostructure morphology seriously. (a)

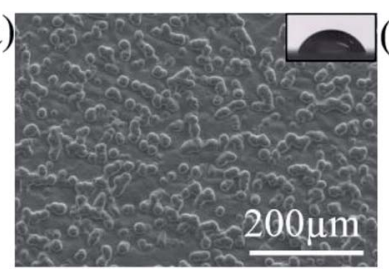

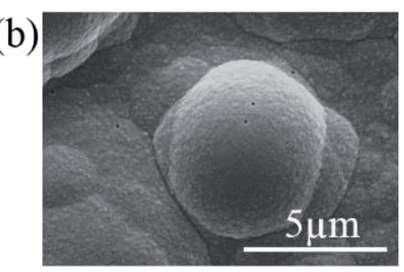

Fig. 2 Surface morphology of electroless $\mathrm{Ni}-\mathrm{P}$ coating.
3.1.1 Temperature dependence. Fig. 3 displays FESEM images of the surface of samples after hydrothermal reaction with different temperatures. During hydrothermal reaction, the nanostructures grew directly on the Ni-P coating in a large area. Clearly the growth habits depend on the temperature and the morphologies of nanostructures change a lot when the reaction temperature gets higher than $100^{\circ} \mathrm{C}$. At lower temperature $(100$ $\left.{ }^{\circ} \mathrm{C}\right)$ the larger particles are synthesized and the particle forms on the substrate alternately and almost covers the defects of Ni-P coating, signifying that defects provide places for the nucleation of the coating because of its higher free energy. The fewer nucleation sites formed and lower supersaturation favor growth by diffusion on steps, and lager particles formed. ${ }^{25,26}$ Finally, the surface was covered by the big lemongrass-like nanostructures. As the reaction temperature increases, the dielectric constant of aqueous solution decreases, as well as a higher degree of supersaturation, more nucleation sites occurred and formed petal-shaped nanosheets with a typical thickness of $\sim 20 \mathrm{~nm}$ and from $120^{\circ} \mathrm{C}$ to $160^{\circ} \mathrm{C}$, the "petals" gradually grew large and loosened. The cross-section morphology of samples of 120 to $160{ }^{\circ} \mathrm{C}$ are shown in Fig. $\mathrm{S} 1, \uparrow$ the nanostructure distribution is layered, and the layer number increasing linearly as the (a)

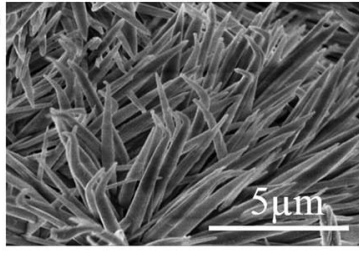

(c)

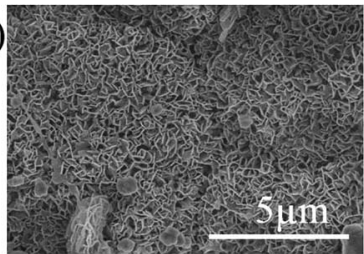

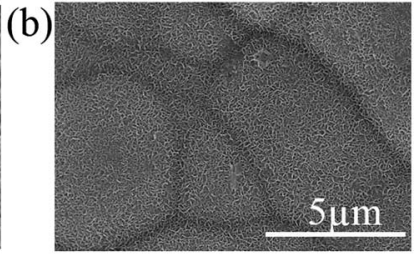

(d)

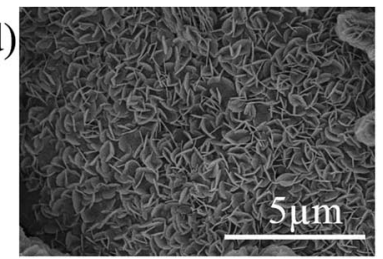

Fig. 3 Surface morphology of sample after hydrothermal reaction at (a) $100^{\circ} \mathrm{C}$, (b) $120^{\circ} \mathrm{C}$, (c) $140{ }^{\circ} \mathrm{C}$, (d) $160^{\circ} \mathrm{C}$ for $15 \mathrm{~h}$. 
temperature rises. The thickness of layered nanostructure up to sub-micro when the temperature higher than $140{ }^{\circ} \mathrm{C}$.

The corresponding static water contact and sliding angles of samples with different hydrothermal temperatures after modification with stearic acid were measured and shown in Fig. 4. At $100{ }^{\circ} \mathrm{C}$, the contact angle and the sliding angle have reached $145.2 \pm 1.7^{\circ}$ and $20^{\circ}$. When the temperature increased to $120^{\circ} \mathrm{C}$, the contact angle further enhanced to $155.6 \pm 0.3^{\circ}$ and the sliding angle decreased to $2^{\circ}$, the surface possessed good superhydrophobicity. But from $140{ }^{\circ} \mathrm{C}$ to $160{ }^{\circ} \mathrm{C}$, the contact angle declined slightly to $146.7 \pm 2.2^{\circ}$ and $134.0 \pm 2.8^{\circ}$, respectively. After hydrothermal reaction, some small hills and valleys are presented on the coating surface. A lot of air could be trapped between the hills or within the coating itself. The hydrophobicity of the surface largely depended on its capacity for trapping air. Compared with large lemongrass-like surface, the small petalshaped nanosheets may be more advantageous. Moreover, the surface prepared under $120^{\circ} \mathrm{C}$ with smaller and compact nanosheets shows excellent superhydrophobicity properties.

3.1.2 Effect of hydrothermal time. The as-prepared surfaces with different hydrothermal reaction times were shown in Fig. 5 (reaction temperature $120^{\circ} \mathrm{C}$ ). From $9 \mathrm{~h}$ to $18 \mathrm{~h}$, the petal-shaped nanosheets have covered the whole surface and gradually grew up and became closer and vertically growing on the top surface. When the reaction time was prolonged to $21 \mathrm{~h}$ and $24 \mathrm{~h}$, the size of nanosheets increased too much and its growth direction looks disordered. The surface all show good superhydrophobic property with the static contact angles above $150.0^{\circ}$, and the sliding angles less than $10^{\circ}$ (see Fig. S2 $\dagger$ ). But at $15 \mathrm{~h}$, the static contact angle reached $155.6 \pm 0.3^{\circ}$ and the sliding angle decreased to $2^{\circ}$, the surface exhibited the optimal superhydrophobicity.

In the search above we found a hydrothermal temperature of $120^{\circ} \mathrm{C}$ and hydrothermal reaction time of $15 \mathrm{~h}$ were the optimal parameters to fabricate superhydrophobic film which was carried out in the following experiments.

\subsection{Chemical composition}

In this section XRD, FT-IR and Raman spectra were utilized to analyze the structure and the formation mechanism of coating.

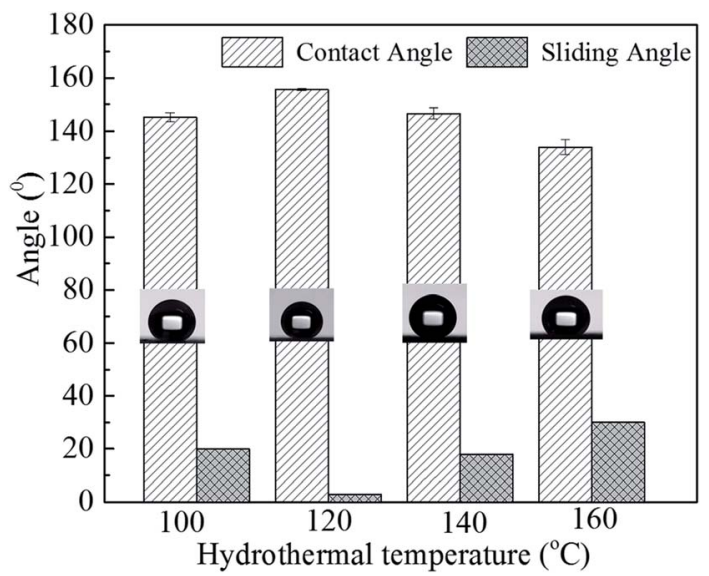

Fig. 4 Variation of water contact angle and sliding angle of superhydrophobic film with hydrothermal temperatures. (a)
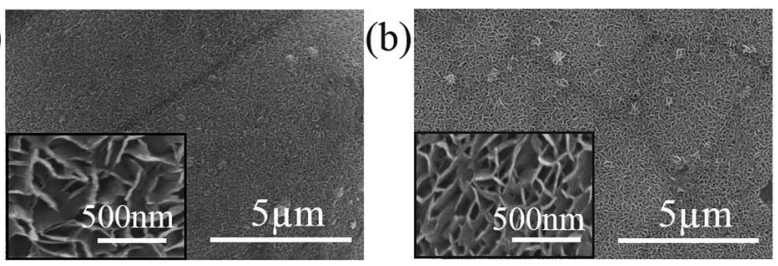

(c)
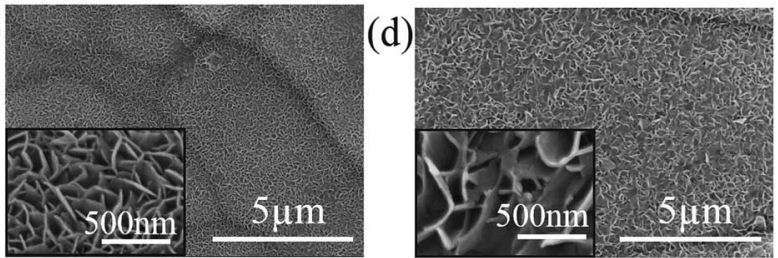

(e)
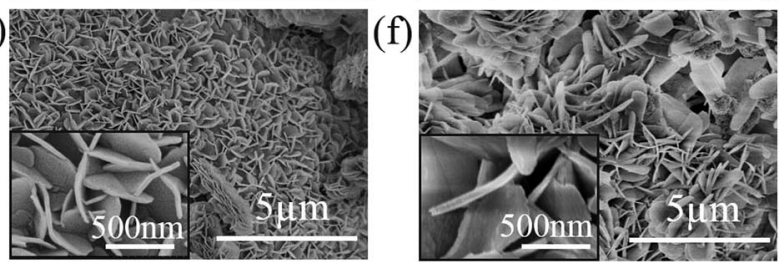

Fig. 5 Surface morphology of samples hydrothermally prepared at $120{ }^{\circ} \mathrm{C}$ for different reaction times: (a) $9 \mathrm{~h}$, (b) $12 \mathrm{~h}$, (c) $15 \mathrm{~h}$, (d) $18 \mathrm{~h}$, (e) $21 \mathrm{~h}$ and (f) $24 \mathrm{~h}$.

In order to simplify representations, the AZ61 substrate, electroless $\mathrm{Ni}-\mathrm{P}$ plating, hydrothermal reaction and stearic acid modification were remarked as S1, S2, S3 and S4. The XRD patterns of $\mathrm{S} 1-\mathrm{S} 4$ were shown in Fig. 6 a. For the $\mathrm{S} 1$, only the typical peaks of $\alpha-\mathrm{Mg}$ and $\beta-\mathrm{Mg}_{17} \mathrm{Al}_{12}$ were detected (the details are given in ESI $\dagger$ ). The XRD pattern of S2 has only a broaden diffraction peak around $44.5^{\circ}$, which belonged to (111) plane of nanocrystalline Ni phase. After hydrothermal reaction, for the $\mathrm{S} 3$, there are diffraction peaks at $13^{\circ}, 26^{\circ}, 34^{\circ}, 36^{\circ}$ and $59^{\circ}$ in accordance with the (001), (002), (100), (101) and (110) planes of $\mathrm{Ni}_{3}\left(\mathrm{NO}_{3}\right)_{2}(\mathrm{OH})_{4}$ (JCPDS no. 22-0752), ${ }^{27}$ obviously for $\mathrm{S} 3$ there exists no other secondary phase. So the generation process of $\mathrm{Ni}_{3}\left(\mathrm{NO}_{3}\right)_{2}(\mathrm{OH})_{4}$ nanosheets can be expressed as follows: ${ }^{27}$

$$
3 \mathrm{Ni}\left(\mathrm{NO}_{3}\right)_{2}+4 \mathrm{H}_{2} \mathrm{O} \rightarrow \mathrm{Ni}_{3}\left(\mathrm{NO}_{3}\right)_{2}(\mathrm{OH})_{4}+4 \mathrm{HNO}_{3}
$$

$\mathrm{Ni}_{3}\left(\mathrm{NO}_{3}\right)_{2}(\mathrm{OH})_{4}$ is derived from the metal hydroxide and has a layered $\mathrm{CdI}_{2}$ structure. ${ }^{28}$ The XRD pattern of $\mathrm{S} 4$ were identical with S3, which indicated that the process of stearic acid modification can not change the coating structure.

Fig. 6b reveals the FT-IR spectra of pure stearic acid, S3 and $\mathrm{S} 4$. For the stearic acid, the peaks at $2844 \mathrm{~cm}^{-1}$ and $2923 \mathrm{~cm}^{-1}$ are attributed to $\mathrm{C}-\mathrm{H}$ asymmetric and symmetric stretching vibrations. The peak at $1708 \mathrm{~cm}^{-1}$ is assigned to the carboxyl groups. Note that the difference between S3 and S4 is two small peaks at $2844 \mathrm{~cm}^{-1}$ and $2923 \mathrm{~cm}^{-1}$ which were attributed to $-\mathrm{CH}_{2}$ or $-\mathrm{CH}_{3}$ functional group on the surface of $\mathrm{S} 4$. It indicates that the surface of S4 has been modified by stearic acid. Other peaks appeared in $\mathrm{S} 3$ and $\mathrm{S} 4$ are assigned to the exist of $\mathrm{Ni}_{3}(-$ $\left.\mathrm{NO}_{3}\right)_{2}(\mathrm{OH})_{4}$, and the details are described in ESI. $\dagger$

Fig. 6c displays the Raman spectra of samples S3 and S4, for $\mathrm{S} 3$, two peaks at $988 \mathrm{~cm}^{-1}$ and $1298 \mathrm{~cm}^{-1}$ are attributed to $-\mathrm{NO}_{3}$ bending vibrations, two other peaks at $2848 \mathrm{~cm}^{-1}$ and 2874 

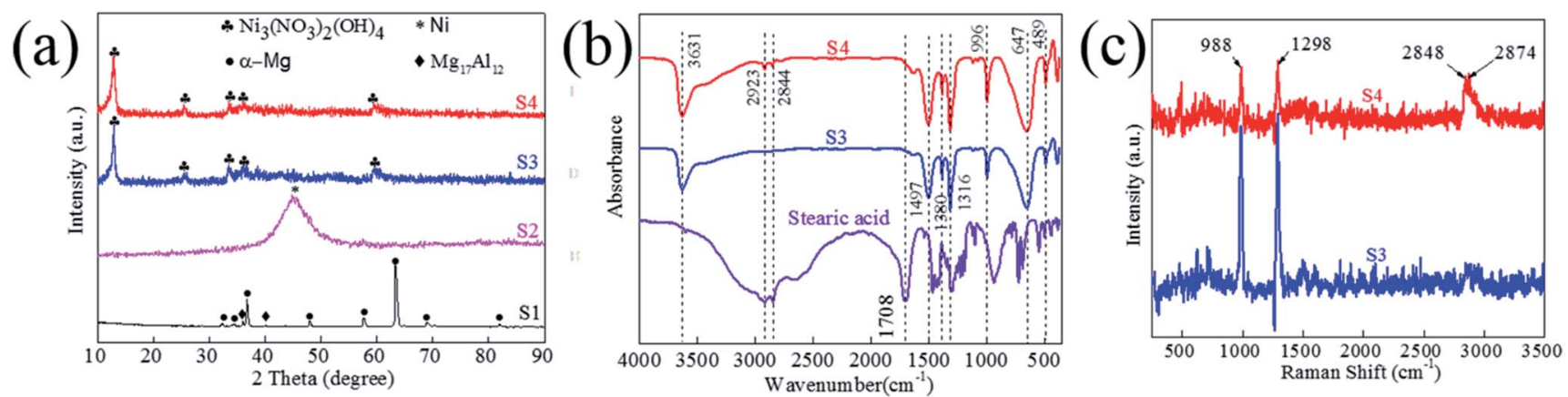

Fig. 6 (a) XRD, (b) FT-IR spectra and (c) Raman spectra of S1 (black color), S2 (magenta color), S3 (blue color) and S4 (red color).

$\mathrm{cm}^{-1}$ of $\mathrm{S} 4$ are attributed to $\mathrm{CH}_{2}$ symmetrical stretching and $\mathrm{CH}_{3}$ symmetrical stretching. ${ }^{29}$ These results also state that stearic acid exists on the sample. As a conclusion, the superhydrophobic film mainly consists of layered $\mathrm{CdI}_{2}$ structure of $\mathrm{Ni}_{3}\left(\mathrm{NO}_{3}\right)_{2}(\mathrm{OH})_{4}$ nanosheets, and stearic acid with low surface energy also existed on the film surface. So the AZ61 alloy, Ni-P coating are hydrophilic $\left(\theta<90^{\circ}\right)$, but the surface turns into superhydrophobic after modification by hydrothermal reaction and stearic acid.

\subsection{Stability}

Fig. 7 shows the relationship between the contact angle and the $\mathrm{pH}$ value, $\mathrm{NaCl}$ concentration and exposure time of the liquid droplets for the superhydrophobic film. From $\mathrm{pH}=2$ to $\mathrm{pH}=$
12 , the contact angles range from $150^{\circ}$ to $156^{\circ}$. It was obvious that the contact angles were still higher than $145^{\circ}$ under strongly acidic and strongly alkali environment. For the various ionic strength $\mathrm{NaCl}$ solutions $\left(1 \mathrm{~mol} \mathrm{~L}^{-1}\right.$ to $\left.5 \mathrm{~mol} \mathrm{~L}^{-1}\right)$, the contact angles were all larger than $150^{\circ}$. Therefore, the superhydrophobicity film can endure a strongly acidic, strongly alkali and high salinity environment. Meanwhile all contact angle of samples was maintained higher than $150^{\circ}$ during air exposure for 180 days. And water was bounded out without any water adhering to the surface after superhydrophobic surface exposed for 180 days (Fig. 7d). These results confirms that the surface has a fine durability in air.

The mechanical stability was tested by an abrasion test as shown in Fig. 8. The superhydrophobic surface was pushed to move on 400 grit sandpaper under a pressure of $9.8 \mathrm{kPa}$, and
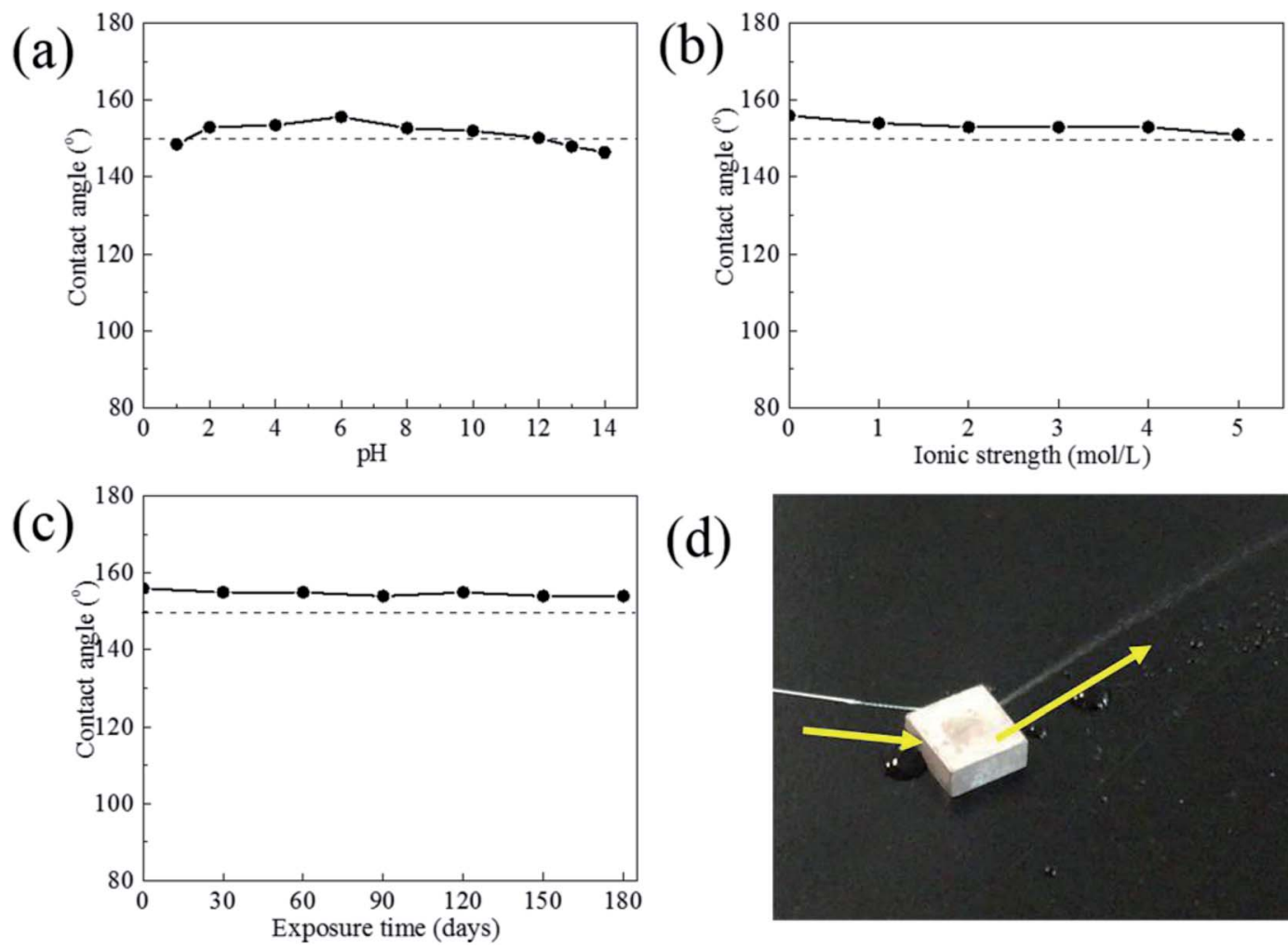

(d)

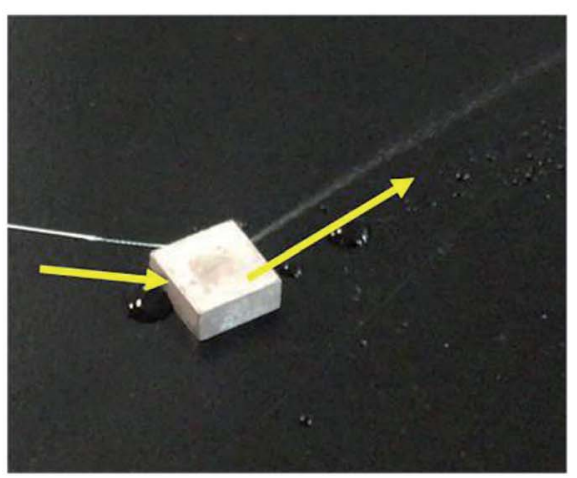

Fig. 7 Contact angle of superhydrophobic film under different condition, (a) pH value, (b) $\mathrm{NaCl}$ concentration (ionic strength), (c) exposure time in air, (d) the bouncing behavior of water jet flow after exposed for 180 days. 


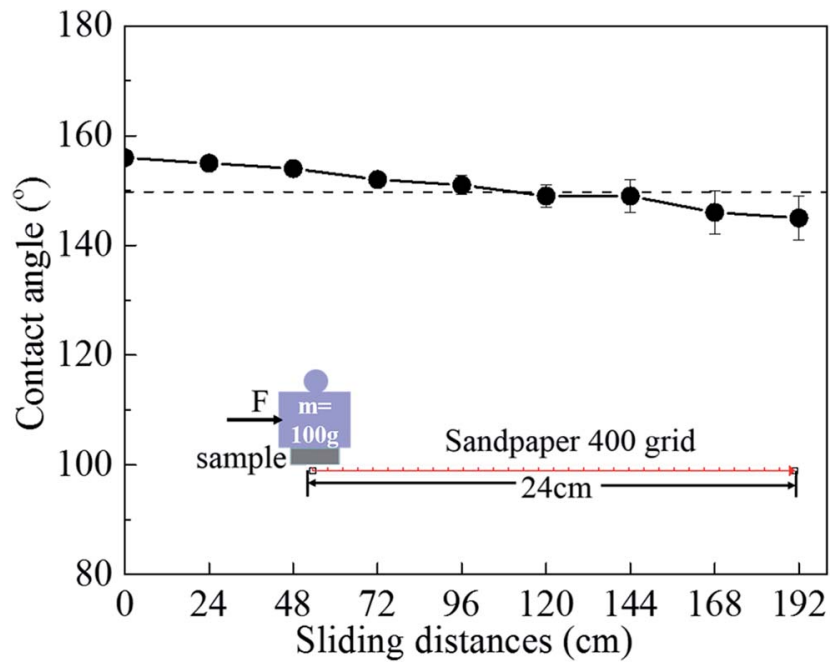

Fig. 8 Contact angles of superhydrophobic film after abrasion test at different lengths.

changes in the contact angle were recorded. The results show that the surface still maintained a contact angle above $150^{\circ}$ after abrasion for $120 \mathrm{~cm}$. However, its value drop down to $145^{\circ}$ after abrasion for $192 \mathrm{~cm}$. Even so, the superhydrophobic surface has good mechanical durability to some extent.

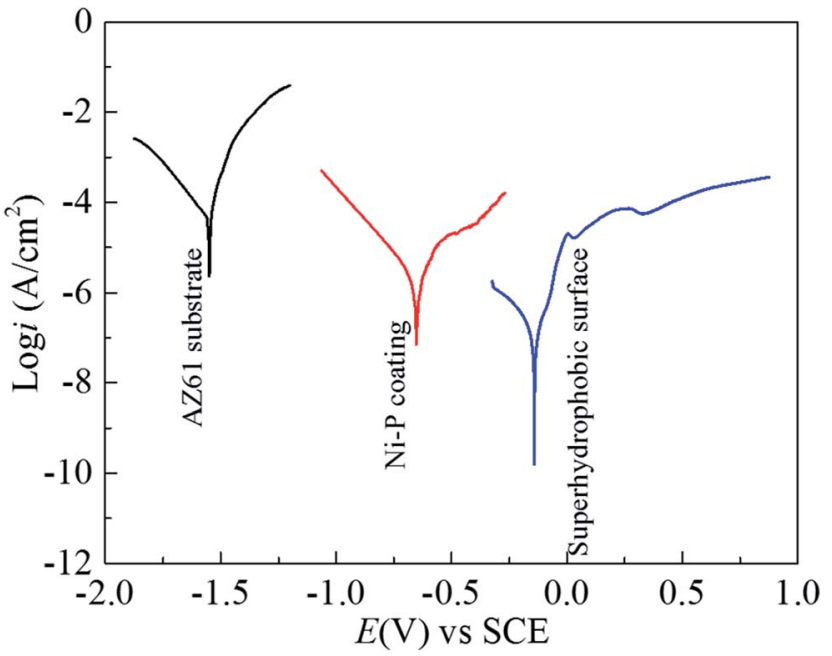

Fig. 10 Polarization curves of AZ61 substrate, Ni-P coating and superhydrophobic film in $3.5 \% \mathrm{NaCl}$ solution.

\subsection{Self-cleaning performance}

The self-cleaning performance of the superhydrophobic surface was investigated by applying alumina powder as contaminant. The self-cleaning evolution process is shown in Fig. 9. The water droplet started to roll down immediately with removing the (a)

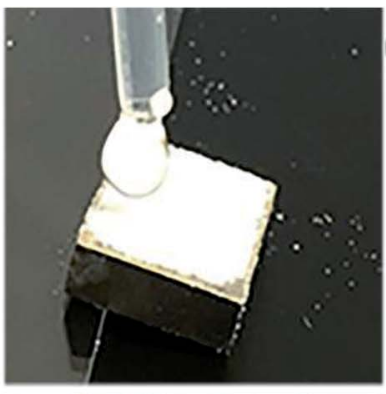

(d)

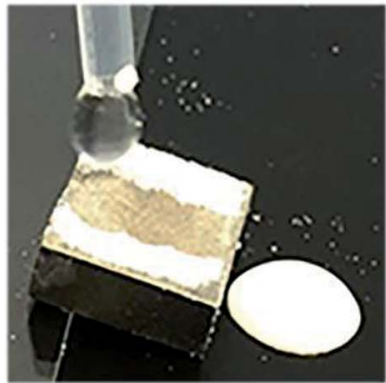

(g)

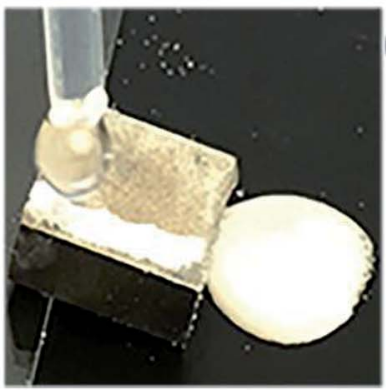

(b)

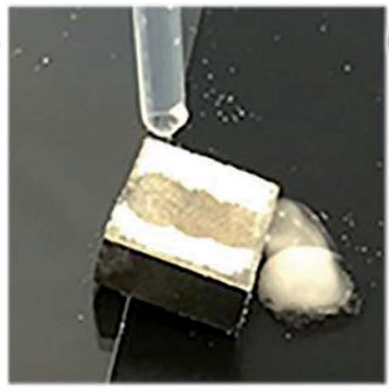

(e)

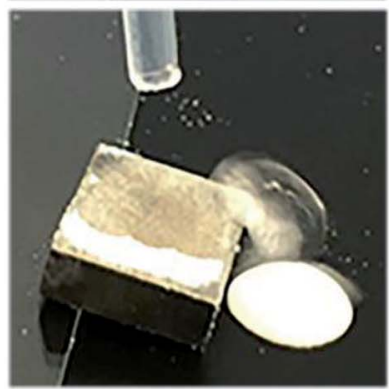

(h)

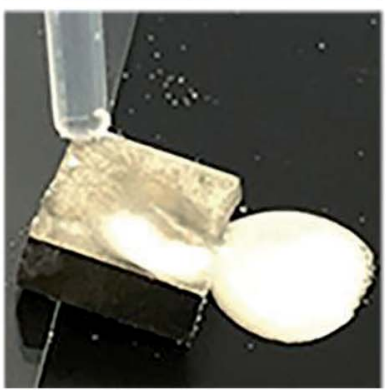

(c)

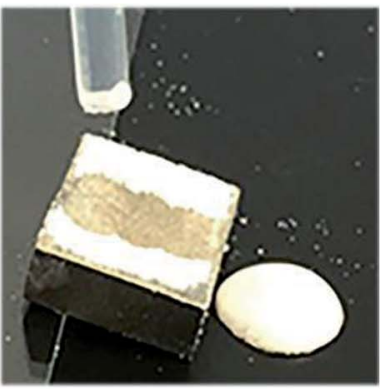

(f)

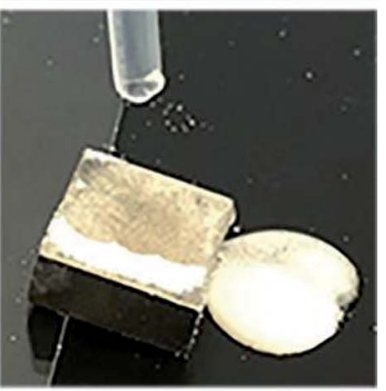

(i)

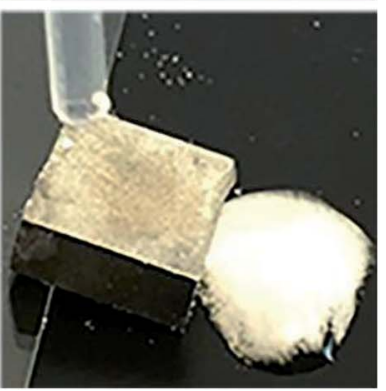

Fig. 9 Self-cleaning behavior of superhydrophobic film. 
contaminant due to weak adhesion of the particle to the superhydrophobic surface and the joint action of capillary forces caused by water droplet. Obviously, the contaminated surface turned clean after three droplets washing. So the as-prepared superhydrophobic surface can protect the substrate from surface contamination.

\subsection{Corrosion resistance characteristics}

Potentiodynamic polarization and impedance spectroscopy (EIS) are used to explain the corrosion behavior of the superhydrophobic film.

Table 1 Corrosion potential, current density and corrosion inhibition efficiency of AZ61 substrate, $\mathrm{Ni}-\mathrm{P}$ coating and superhydrophobic film in $3.5 \% \mathrm{NaCl}$ solution by polarization curve

\begin{tabular}{llll}
\hline Sample & $E_{\text {corr }}(\mathrm{mV})$ & $i_{\text {corr }}\left(\mu \mathrm{A} \mathrm{cm}^{-2}\right)$ & $\eta_{\mathrm{p}}(\%)$ \\
\hline AZ61 substrate & -1548.0 & 35.3 & - \\
Ni-P coating & -656.7 & 19.8 & 43.9 \\
Superhydrophobic & -139.3 & $7.2 \times 10^{-2}$ & 99.8
\end{tabular}

3.5.1 Potentiodynamic polarization curves. Fig. 10 is the polarization curves of AZ61 substrate, Ni-P coating and superhydrophobic film in $3.5 \% \mathrm{NaCl}$ solution, and the corrosion potential $\left(E_{\text {corr }}\right)$, current density $\left(i_{\text {corr }}\right)$ and corrosion inhibition efficiency $\left(\eta_{\mathrm{p}}\right)$ of samples are shown in Table 1. $\eta_{\mathrm{p}}$ which is related to $i_{\text {corr }}$, is calculated with using following equation: $:^{\mathbf{3 0 , 3 1}}$

$$
\eta_{\mathrm{p}}(\%)=\frac{i_{\text {corr }}^{0}-i_{\text {corr }}}{i_{\text {corr }}^{0}} \times 100
$$

where $i_{\text {corr }}^{0}$ and $i_{\text {corr }}$ are the corrosion current density values without and with the coating, respectively. Compared with AZ61 substrate, the corrosion potential and the corrosion inhibition efficiency is increased, and current density decreased because of Ni-P coating, which indicates that the corrosion resistance of AZ61 alloy is enhanced by the deposition of Ni-P coating.

And, more remarkably, the superhydrophobic film has the highest $E_{\text {corr }}(-139.3 \mathrm{mV})$ and $\eta_{\mathrm{p}}(99.8 \%)$, also has the lowest $i_{\text {corr }}\left(7.2 \times 10^{-2} \mu \mathrm{A} \mathrm{cm}^{-2}\right)$. This result indicates that the superhydrophobic film exhibits excellent protective ability to AZ61 film
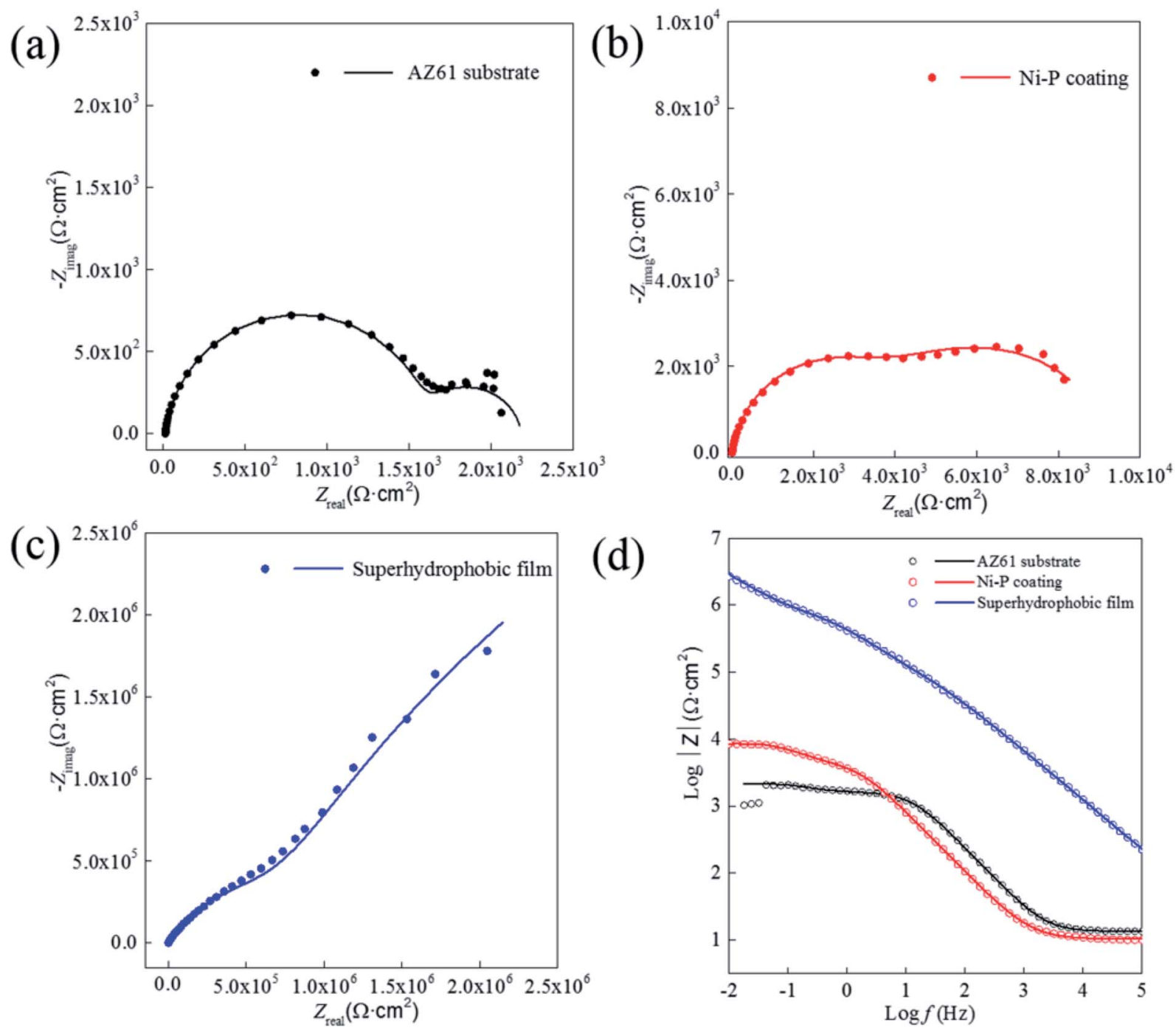

Fig. 11 ElS spectrum of $\mathrm{AZ} 61$ substrate, $\mathrm{Ni}-\mathrm{P}$ coating and superhydrophobic film in $3.5 \% \mathrm{NaCl}$ solution. 
substrate, and magnesium dissolution and $\mathrm{Cl}^{-}$transports are strongly restrained by the superhydrophobic film.

3.5.2 Electrochemical impedance spectroscopy. Fig. 11 is the EIS spectrum of AZ61 alloy, Ni-P coating and superhydrophobic film after immersion in $3.5 \mathrm{wt} \% \mathrm{NaCl}$ solution for $0.5 \mathrm{~h}$. It is well known that a large Nyquist loop means a lower corrosion rate. ${ }^{15}$ The diameter of the Nyquist loop of the superhydrophobic film is significantly larger than that of AZ61 alloy and $\mathrm{Ni}-\mathrm{P}$ coating (Fig. 11a-c), indicating the corrosion resistance has been greatly enhanced with the presence of superhydrophobic film. In addition, the corrosion rate can also be estimated from the value of $|Z|_{f \rightarrow 0}$ in the modulus Bode plots (Fig. 11d), in that a higher value of $|Z|_{f \rightarrow 0}$ is indicative of a lower corrosion rate..$^{32}$ The value of $|Z|_{f \rightarrow 0}$ for AZ61 alloy increases from $\sim 2.1 \times 10^{3} \Omega \mathrm{cm}^{2}$ to $\sim 8.5 \times 10^{3} \Omega \mathrm{cm}^{2}$ with Ni-P coating, and further increases to $\sim 2.8 \times 10^{6} \Omega \mathrm{cm}^{2}$ with superhydrophobic film. For EIS spectrum in Fig. 11, the equivalent circuits in Fig. $\mathrm{S} 3 \dagger$ were applied to analyse the experimental date, in which $R_{\mathrm{S}}$ is the solution resistance, $\mathrm{CPE}_{\text {coat }}$ and $R_{\text {coat }}$ are the double electric layer capacitance and charge transfer resistance of $\mathrm{Ni}-\mathrm{P}$ coating (oxide layer for AZ61 substrate), $\mathrm{CPE}_{\text {super }}$ and $R_{\text {super }}$ are the double electric layer capacitance and charge transfer resistance of superhydrophobic film and $\mathrm{CPE}_{\mathrm{dl}}$ and $R_{\mathrm{ct}}$ are the double electric layer capacitance and charge transfer resistance of AZ61 substrate. The fitting curves are displayed as solid lines in Fig. 11, and the fitting parameters is shown in Table S1. $\dagger$ It can be seen that AZ61 substrate has a lower $R_{\mathrm{ct}}$ about $1.6 \times 10^{3} \Omega \mathrm{cm}^{2}$, and $R_{\mathrm{ct}}$ reaches to $3.4 \times 10^{3} \Omega \mathrm{cm}^{2}$ after plating Ni-P coating. However, the superhydrophobic coating has the highest of $R_{\mathrm{ct}}$ of $1.1 \times 10^{7}$ $\Omega \mathrm{cm}^{2}$, especially the resistance of superhydrophobic film reaches to $5.8 \times 10^{5} \Omega \mathrm{cm}^{2}$, a powerful force to block the entry of electrolyte. Above all, the EIS results indicate the superhydrophobic surface is a robust blocking layer for preventing the rapid corrosion on substrate in contact with $\mathrm{NaCl}$ solution, which agrees well with the results of Tafel.

\section{Conclusions}

The petal-shaped $\mathrm{Ni}_{3}\left(\mathrm{NO}_{3}\right)_{2}(\mathrm{OH})_{4}$ nanostructure grows on electroless Ni-P coating surface of AZ61 magnesium alloy using hydrothermal method, and the surface changes from a hydrophilic one to superhydrophobic after modification by hydrothermal reaction and stearic acid. The superhydrophobic film exhibits high chemical stability, mechanical durability and self-cleaning performance. The corrosion resistance of the superhydrophobic coating improved nearly 3 orders than AZ61 magnesium alloy and electroless Ni-P coating in $3.5 \% \mathrm{NaCl}$ solution. It is believed that fabricating a superhydrophobic surface may be a novel approach to enhance the corrosion resistance and expand the application of magnesium alloys. At the same time, this study provided an efficient method to fabricate superhydrophobic surface with robust corrosion resistance on other metals.

\section{Acknowledgements}

This paper was supported by National Natural Science Foundation of China (No. 51471117), Key Project of Tianjin Natural
Science Foundation (13JCZDJC29500), Natural Science Foundation of Qinghai province (No. 2015-HZ-811) and Independent Innovation Fund Cooperation Project between Tianjin University and Qinghai University for Nationalities (1606).

\section{References}

1 H. W. Huo, Y. Li and F. H. Wang, Corros. Sci., 2004, 46, 14671477.

2 X. W. Guo, S. H. Wang, J. Gong, J. C. Guo, L. M. Peng and W. J. Ding, Appl. Surf. Sci., 2014, 313, 711-719.

3 Y. J. Zhang, Y. W. Shao, T. Zhang, G. Z. Meng and F. H. Wang, Corros. Sci., 2011, 53, 3747-3755.

4 H. Y. Yang, X. W. Guo, X. B. Chen and N. Birbilis, Corros. Sci., 2014, 79, 41-49.

5 D. Veys-Renaux, C. E. Barchiche and E. Rocca, Surf. Coat. Technol., 2014, 251, 232-238.

6 Z. P. Zhang, G. Yu, Y. J. Ouyang, X. M. He, B. N. Hu, J. Zhang and Z. J. Wu, Appl. Surf. Sci., 2009, 255, 7773-7779.

7 I. Saeki, T. Seguchi, Y. Kourakata and Y. Hayashi, Electrochim. Acta, 2013, 114, 827-831.

8 G. Y. Wang, Y. Z. Shen, J. Tao, X. Y. Luo, L. Q. Zhang and Y. P. Xia, RSC Adv., 2017, 7, 9981-9988.

9 T. C. Chen, H. T. Liu, H. F. Yang, W. Yan, W. Yan, W. Zhu and H. Liu, RSC Adv., 2016, 6, 43937-43949.

10 S. A. Kulinich, S. Farhadi, K. Nose and X. W. Du, Langmuir, 2011, 27, 25-29.

11 M. Zhou, X. L. Pang, L. Wei and K. W. Gao, Appl. Surf. Sci., 2015, 337, 172-177.

12 J. Li, R. M. Kang, Y. Zhang, M. J. Li, H. D. She, F. Zha and Z. Q. Lei, RSC Adv., 2016, 6, 90824-90830.

13 G. C. Zhao, Y. P. Xue, Y. F. Huang, Y. Ye, F. Walsh, J. Chen and S. C. Wang, RSC Adv., 2016, 6, 59104-59112.

14 Y. Liu, X. M. Yin, J. J. Zhang, Y. M. Wang, Z. W. Han and L. Q. Ren, Appl. Surf. Sci., 2013, 280, 845-849.

15 X. J. Cui, X. Z. Lin, C. H. Liu, R. S. Yang, X. W. Zheng and M. Gong, Corros. Sci., 2015, 90, 402-412.

16 Y. J. Fu, X. W. Li, X. L. Sun, X. H. Wang, D. Q. Liu and D. Y. He, J. Mater. Chem., 2012, 22, 17429-17431.

17 X. H. Wang, L. Qiao, X. L. Sun, X. W. Li, D. K. Hu, Q. Zhang and D. Y. He, J. Mater. Chem. A, 2013, 1, 4173-4176.

18 J. F. Ou, W. H. Hu, M. S. Xue, F. J. Wang and W. Li, ACS Appl. Mater. Interfaces, 2013, 5, 3101-3107.

19 H. R. Wan and X. F. Hu, Mater. Lett., 2016, 174, 209-212.

20 X. M. Zhang, G. S. Wu, X. Peng, L. M. Li, H. Q. Feng, B. Gao, K. F. Huo and P. K. Chu, Sci. Rep., 2015, 5, 17399.

21 Z. W. Wang, Y. L. Su, Q. Li, Y. Liu, Z. X. She, F. N. Chen, L. Q. Li, X. X. Zhang and P. Zhang, Mater. Charact., 2015, 99, 200-209.

22 M. Zhou, X. L. Pang, L. Wei and K. W. Gao, Appl. Surf. Sci., 2015, 337, 172-177.

23 Z. J. Li and Y. Yuan, RSC Adv., 2016, 6, 90587-90596.

24 Q. Liu, D. X. Chen and Z. X. Kang, ACS Appl. Mater. Interfaces, 2015, 7, 1859-1867.

25 C. H. Lu and C. H. Yeh, Ceram. Int., 2000, 26, 351-357.

26 M. SØndergaard, E. D. BØjesen, M. Christensen and B. B. Iversen, Cryst. Growth Des., 2011, 11, 4027-4033. 
27 L. B. Kong, L. Deng, X. M. Li, M. C. Liu, Y. C. Luo and L. Kang, Mater. Res. Bull., 2012, 47, 1641-1647.

28 J. Y. Miao, M. Xue, H. Itoh and Q. Feng, J. Mater. Chem., 2006, 16, 474-480.

29 N. K. Howell, G. Arteaga, S. Nakai and E. Y. Li-Chan, J. Agric. Food Chem., 1999, 147, 924-933.
30 Y. Liu, S. Y. Li, J. J. Zhang, J. Liu, Z. W. Han and L. Q. Ren, Corros. Sci., 2015, 94, 190-196.

31 D. Daoud, T. Douadi, S. Issaadi and S. Chafaa, Corros. Sci., 2014, 79, 50-58.

32 T. S. Lim, H. S. Ryu and S. H. Hong, Corros. Sci., 2012, 62, 104-111. 